\title{
EXPERIENCIA DE LA MASCULINIDAD: LA VISIÓN DE UN GRUPO DE HOMBRES GUATEMALTECOS
}

EXPERIENCE OF MASCULINITY: THE VISION OF A GROUP OF GUATEMALAN MEN

Recibido: 02 de Marzo del 2011 | Aceptado: 21 de Noviembre del 2011

SANDRA E. LUNA ${ }^{1}$

(UNIVERSIDAD DEL VALLE DE GUATEMALA, Guatemala).

\begin{abstract}
RESUMEN
Este estudio cualitativo responde a la pregunta de cómo es la experiencia de ser hombre, el significado que tiene, la forma como lo comprenden y adquieren su identidad masculina, un grupo de hombres guatemaltecos mayores de edad dentro de la sociedad guatemalteca. El enfoque teórico que se utilizó es el fenomenológico hermenéutico y el enfoque psicológico para la interpretación fue el biopsicosocial. Se realizaron dos grupos focales. La forma de reclutamiento de los participantes fue por bola de nieve. Los hallazgos sugieren que la experiencia está vinculada al modelo machista y la imitación al modelaje del padre.
\end{abstract}

PALABRAS CLAVE: Identidad; masculinidad; hombre.

\section{ABSTRACT}

This qualitative study answered the question "How is the experience of being a man, the meaning, the way they understand and develop their masculine identity within Guatemalan society of a group of Guatemalan adult men. The theoretical approach that was used is the hermeneutic phenomenological and psychological approach to the interpretation was the biopsychosocial. We conducted two focus groups; recruitment was by way of snowballing. Findings suggested that the experience is linked to male model and modeling imitation of the father.

KEY WORDS: Identity, masculinity, man. 


\section{INTRODUCCIÓN}

Este estudio tiene interés sobre la vivencia de los hombres, cómo se sienten como hombres y cómo se ven influenciados para ser y comportarse. Refieren Salas y Campos (2005) que no se nace hombre, sino macho de la especie humana y que se hacen hombres por un proceso de socialización y de construcción de la identidad masculina que supone unas características específicas.

Los estudios sobre los varones pueden ayudarnos a conocer la visión que tienen y ante qué se enfrentan, para deconstruir y construir una masculinidad nueva. El concepto de machismo está arraigado en la cultura; estudiarlo nos da un panorama de cómo es la visión que el hombre tiene de sí mismo y si ha tomado conciencia de lo que la sociedad le impone.

En Guatemala han sido muy pocos los esfuerzos que se han hecho en este tema, de hecho en un encuentro sobre masculinidades en 2009 surgieron algunas propuestas que no se han concretado.

\section{Masculinidad en Centro América y su trayectoria}

Campos y Salas (2002), muestran una compilación de los artículos que hasta ese momento se habían realizado en el trabajo con hombres en Centroamérica. Sin embargo, es importante señalar que hay muchos esfuerzos que no se han publicado. Liendro (2002), refiere que es a partir de los años 90' cuando se inician las diferentes experiencias de trabajo colectivo con hombrees en la región con un enfoque crítico y a veces de género. De igual manera las instituciones públicas y organizaciones sociales incluyeron el tema por su relación con la salud sexual y reproductiva, la violencia doméstica y la paternidad. Según refiere Liendro (2002) ha sido gracias al empuje, presión e interés de las organizaciones de mujeres que los hombres se han reunido para reflexionar. Sin embargo, considera que se ha perdido el interés por la falta de una actitud más crítica y de diálogo entre las organizaciones que trabajan con hombres.

En Nicaragua, Abaunza (2002), hizo referencia, a un programa que se llama Puntos de Encuentro sobre masculinidad y violencia, fundación feminista mixta que tiene como eje el análisis de las relaciones de poder en la vida cotidiana y que busca pistas para prevenir la violencia masculina en las relaciones de pareja. Su trabajo es la experiencia de los "no violentos" para encontrar nuevos elementos que ayuden a realizar un trabajo educativo con hombres que maltratan. Los facilitadores de estas prácticas buscaron alcanzar la autoconciencia, argumentos y razonamientos para reforzar comportamientos no violentos, redes de apoyo, cualidades personales tales como: hogareño y autocrítico. Los beneficios redundan en mejores relaciones intrafamiliares, buena reputación y sentirse bien como hombre.

Reyes (2002) en León, Nicaragua reportó en su estudio con 448 mujeres, que el $60 \%$ sufrió de abuso físico o psicológico. El autor indica que el maltrato a las mujeres no es provocado por hombres malos, sino que cualquiera puede ejercerlo dependiendo de las circunstancias de la vida e indica que mientras se viva en una cultura que dicta y justifica el maltrato hacia las mujeres, el ejercer la violencia puede ser una tentación. Otras organizaciones que trabajan el tema en Nicaragua son: CANTERA, CISAS y CIPRES, algunas ONGs trabajan la equidad de género.

Por su parte Montesdeoca (2002), dice que en Honduras la construcción de la masculinidad está marcada históricamente por la imagen del liderazgo que oscila entre el guerrero y el patriarca. Los trabajos realizados iniciaron en el 1995 y se han limitado al tema de la violencia y salud sexual reproductiva. 
Ministerio de Educación de San Salvador, El Salvador plantea que ha creado el Programa de Educación para la Vida, que tiene un enfoque preventivo integral (Estrada,2002). La masculinidad se ha tratado en un Plan de Capacitación Institucional sobre el enfoque de género, que está dirigido tanto a la población femenina como masculina.

En Guatemala, Galván, de Asociación de Apoyo Integral ( $\mathrm{ACl})$, escribe que aunque actualmente las mujeres denuncian más los hechos violentos, esto no implica que la violencia haya disminuido En 1998 el Ministerio de Educación implementó un plan de capacitación para maestros, pero no fue una política horizontal en todo el Ministerio y cuando los fondos terminaron, terminó la capacitación.

La violencia contra los hombres es vista como degradante, por lo que sus denuncias son menores. Las cifras de estas denuncias realizadas, tanto de violentadores como de violentados difieren del Sistematización y Fortalecimiento del Programa de Prevención y Erradicación de la Violencia Intrafamiliar (PROPEVI) al Ministerio Público de forma considerable, dado que en el primero no están vinculadas a la justicia. El trabajo más reconocido en Guatemala ha sido el orientado a mitigar la violencia intrafamiliar. $\mathrm{ACl}$ se ha dedicado desde su creación a realizar acciones de reflexión y conformación de grupos de apoyo en el tema de la masculinidad. Hasta ahora no existen políticas públicas para la atención en este tema. Las experiencias que presentan tanto Buc (2002) como Pérez (2002) mencionan la dificultad debido al sistema patriarcal imperante, según Buc desde las religiones $y$ de la falta de demanda política concreta.

Es interesante constatar que todos los estudios, esfuerzos, actividades y textos que se han realizado en Centro América responden al hombre violento, perpetrador de la violencia intrafamiliar.
Estudios sobre masculinidades en América Latina

Toro-Alfonso (2009), en un recorrido sobre la trayectoria de los estudios de la masculinidad, refiere que en los ochenta ya se desarrollan modelos más críticos que dieron paso a investigaciones más sofisticadas en el análisis de la masculinidad. Es en este momento que se acuña el concepto de "masculinidad hegemónica". Este término refería una contraposición a lo subordinado, mostrando relaciones asimétricas en donde el hombre se consideraba superior a la mujer, de la misma forma que la heterosexualidad superior a la homosexualidad.

También, el autor indica que los estudios que se han realizado en América Latina sobre el tema han hecho grandes aportaciones. Los trabajos sobre el machismo que Ramírez (1993) y De la Cancela (1986) realizaron han sido de gran impacto porque muestran de qué forma la cultura estadounidense percibe las relaciones hombre - mujer y de qué manera este describe el comportamiento masculino.

Luego de dar un recorrido por lo histórico visualizamos un panorama de lo que socialmente se está definiendo como masculinidad. El concepto del hombre aparece muy ligado a la violencia. Guerra y Toro-Alfonso (2009) plantean que es el construccionismo social lo que define el concepto y que las expresiones de "hombre", "mujer" y "masculino" las definen los usos sociales.

Por tanto, el género sería el conjunto de roles y normas sancionado socialmente, asignados dependiendo del sexo biológico, que es dado e incuestionable. Según indican Cornwall y Lindisfarne (1994), citados por Espada (2004) la triada a que se enfrenta es: macho - hombre masculinidad, términos que no se sobreponen, cada uno tiene múltiples referentes que desdibujan, cualifican y 
crean posibilidades de interpretación que pueden ser ambiguas dependiendo de los escenarios sociales. Sin embargo, el uso de categorías como virilidad- hombría masculinidad están sujetas a varias premisas. Las identidades de género dependen de tener una serie de atributos socialmente apropiados. La orientación sexual "normal" está supeditada a la anatomía, comportamiento y deseos, entre tejiendo que la aceptada es la heterosexualidad coital.

Espada (2004), plantea la definición de "masculinidad hegemónica" como las ideologías que atribuyen al hombre ciertas formas privilegiadas de poder y exitosas de "ser hombre", marcando otros estilos de ser hombre como inadecuados o como les llama Cardigan, Connell y Lee (en Espada, 2004), "variantes subordinadas" (p. 1). El autor cita a Connell (1995), refiriendo los conceptos para examinar las diferentes formas de masculinidad: "dividendo patriarcal", término que indica las ventajas que tienen los hombres sobre las mujeres en relación a mejores salarios y formas de promoción. Por otro lado, la "masculinidad hegemónica" que es la masculinidad dominante culturalmente autorizada $y$ autorizante por el orden establecido que puede decirse que es la sociedad.

La paternidad es un tema que define al hombre, como señala Parrini (2000), al reflexionar sobre las imágenes y la importancia entre ésta y la masculinidad, en la formación de la subjetividad. Presenta dos dimensiones citando a (Tubert, 1997) que son: primero el orden socio-cultural, el universo simbólico de las categorías, representaciones, modelos e imágenes del padre que según refiere forman parte del sistema social, político e ideológico, dado por la historia y que organiza la subjetividad del ser humano. Segundo, a la vez la construcción de la subjetividad presenta dos dimensiones: un imaginario colectivo y uno particular, elaborado por la singularidad del sujeto.
Continúa el autor que para comprender la paternidad es necesario contemplar tres campos: las relaciones de género, la construcción de la masculinidad y las relaciones de poder. Basándose de nuevo en (Tubert, 1997) habla de tres premisas: la paternidad es una construcción cultural, por lo que tiene un carácter histórico. No se comprende sino es en relación con la maternidad, sólo tiene sentido en el sistema del parentesco y el parentesco a la vez se sitúa en universo simbólico. Por tanto, la función paterna es una función de poder, en la relación paterno-filial el poder es la fuerza que la mueve en sus muchas representaciones. El padre es el garante de la filiación y da al individuo un lugar social. De esta manera el modelo hegemónico de la masculinidad se ordena alrededor de la función paterna, la figura central es el padre. Parrini (2000), asevera que

"El padre es la culminación de la
identidad masculina, la inicia
y la termina. De niño ante mi
propio padre y de adulto ante el
propio hijo" (p. 75).

A los hombres se les ha reprimido culturalmente la expresión de ciertos sentimientos y emociones, que se atribuyen a lo femenino dicen Rodríguez-Ramírez y Toro Alfonso (2009). Las expresiones emocionales son parte de la reproducción de categorías específicas del sujeto tales como: género, clase, sexualidad y raza, estando implícitas las relaciones de poder que las constituyen. Los autores aducen que el proponer que las emociones responden a estas diferenciaciones, hace abandonar la idea de que éstas son posesiones individuales, universales 0 biológicas. Y por ende, estas son diferentes en los hombres y mujeres, diferencias que responden a las asignadas por la cultura a cada género.

Rodríguez-Ramírez y Toro-Alfonso (2009) citan a Toro-Alfonso y Varas Díaz (2006), quienes plantean que no todos los 
hombres son iguales y que hay algunos que retan las construcciones propias de la hegemonía y que buscan la diferencia, ya que no se conforman con esa visión tradicional. Ampliando citan a Janz (2000), que indica que la inhibición de las emociones entre hombres no es natural, es resultado de la carencia en la práctica.

Olavarría (2001), refiere que según diversos estudios, ser hombre, desde el nacimiento es una "gracia", pero se requiere que sea: responsable, recto y está obligado a comportarse correctamente, lo que significan atributos de alto contenido moral. Ser digno y solidario, especialmente con su familia y amigos, protector de débiles que están bajo su dominio. Debe ser una persona autónoma, libre, debe dar siempre la imagen de que es seguro y saber lo que hace. Debe ser fuerte, racional, económicamente controlado, valiente, no desviarse de su curso por sentimientos, no demostrar debilidad. Debe estar dispuesto a competir con otros hombres para demostrar sus capacidades físicas y si es posible ganar. El hombre es de la calle, allí tiene que buscar el sustento de su familia.

Hartog (2006), se plantea la interrogante sobre la construcción social de la masculinidad desde las ciencias sociales. Refiere que las ciencias del hombre, los estudios sobre la mujer y los de género son las corrientes teóricas que han abierto la brecha para entender mejor de qué manera la hombría puede frenar o impulsar cambios radicales en vías de un mejor humanismo.

Olavarría (2001) y Olavarría y Parrini, (2000), proponen que las propuestas de género vienen de una dimensión constitutiva de las relaciones sociales y de la cultura, construcciones que se han denominado sistema de sexo/género, en donde la anatomía/fisiología, por la manera de responder a los impulsos sexuales, es la que establece en las personas, las relaciones en la trama social.
La característica central de la masculinidad hegemónica es la heterosexualidad, lo que es autorizado para que el deseo sexual de los hombres pueda ser más fuerte que su voluntad. Existen mandatos para los hombres y desde la infancia se les refuerza que tienen que "hacerse hombres" y para cumplir con este mandato tienen que seguir ciertos atributos que según refieren los hombres les traen problemas, les dificultan la relación de pareja y de familia, les frustran en sus deseos y aspiraciones y les producen dolor. La competencia por poder, prestigio, fuerza, inteligencia y especialmente por las mujeres, competir con las mujeres o actuar de otro modo, trasgrediendo los límites de lo femenino es denigrante. El proceso de convertirse en adulto conlleva un ritual que pasa por: sostener su primera relación sexual, tener un trabajo remunerado y convertirse en padre de un hijo. Esta forma de ser hombre se vuelve "natural" por lo que hay invisibilidad de las relaciones de poder entre el hombre y la mujer y entre otros hombres.

La violencia masculina se presenta en una tríada: violencia contra las mujeres, contra otros hombres y contra sí mismos, violencia que se da por la institucionalización del manejo de los aspectos de la vida, tanto social, económica y política. Las formas como los varones construyen el poder social e individual es paradójica, lo que provoca dolor, porque preservan tan fuertemente su hombría cargada de un sentimiento general de inseguridad por no poder realizar las expectativas interiorizadas.

Es importante situar en el contexto de las relaciones de poder, los estudios, análisis y trabajos sobre el tema de la violencia y masculinidad; como ejes centrales el tema de poder, la dominación y el control. Se puede concluir que la importancia de entender que la violencia se hace parte de la identidad masculina, se construye social e históricamente, no es una condición natural. 
La violencia es vista como una expresión extrema de desigualdad de género, reproducida generacionalmente.

Connell (2009), dice que no se puede hacer de la masculinidad una ciencia generalizadora, que al definir masculinidad se puede hacer notar que todas las sociedades cuentan con registros culturales de género pero no todas tienen un concepto de masculinidad.

Hay cuatro enfoques que se distinguen en la conceptualización del término, los cuales no son abarcadores, pero han marcado un sentido. El enfoque esencialista recoge un rasgo masculino y lo une a varios rasgos de la vida de los hombres, sin embargo es arbitrario. Las ciencias sociales y su postura positivista hablan de una definición simplista, lo que los hombres realmente son. Esta definición es la base lógica de las escalas de pruebas psicológicas y son básicas para la validación de los grupos: hombres 0 mujeres, sin embargo es base de discusiones pues presentan unos rasgos característicos de una cultura en particular, por que muestran que resulta un "modelo de masculinidad".

Connell (2009), expresa que para definir la masculinidad como un objeto hay que centrarse en los procesos y relaciones por los cuales los hombres y mujeres llevan vidas inmersas en el género. La masculinidad es una posición en las relaciones de género, las prácticas por las que se compromete a esa posición y los efectos de esas prácticas en la experiencia corporal, la personalidad y la cultura.

La sociedad es cambiante y actualmente se ha visto inmersa en la globalización, fenómeno que ha hecho su efecto también en los hombres, que en su cotidianidad están inmersos en múltiples roles, especialmente en el ámbito laboral. Olavarría (2008) citando a Beck, Hardt, Negri y De Souza (2008), indica que los cambios que ha producido, inserta a los países y sus habitantes en procesos culturales profundamente contradictorios.

El concepto de masculinidad hegemónica, el de machismo y el sistema patriarcal, han confrontado la experiencia y de ese enfrentamiento a se ha generado un deseo por el cambio, en busca de una equidad de género. Sin embargo, la construcción de la sociedad le ha impuesto a los hombres papeles que se siente obligado a cumplir, pues de lo contrario, la construcción de su ser hombre no está completa. Espada (2004) y Connell (1995) hacen ver que el cumplir con lo requerido por la sociedad, da al hombre privilegios de poder y exitosas formas de "ser hombre".

Este trabajo responde, a la necesidad de respondernos sobre el actuar de los hombres en Guatemala. El interrogante es ¿Cómo es la experiencia de ser hombre, el significado que tiene, la forma cómo lo comprenden y cómo adquieren su identidad masculina, hombres guatemaltecos?

\section{MÉTODO}

La investigación fue cualitativa, con un enfoque epistemológico basado en la fenomenología hermenéutica. La investigación se orientó a la experiencia vivida (fenomenología) y a la interpretación de "textos" de vida siguiendo una interrelación dinámica enfocada en el fenómeno de cómo viven la experiencia de la masculinidad los hombres guatemaltecos. Se abordó desde un enfoque de género que identifica, analiza las formas de acción a asumir para tratar las desigualdades que existen en los roles entre hombres y mujeres y el desequilibrio de las relaciones de poder y las consecuencias en sus vidas, en su salud y bienestar (Marsellés,2005).

Se utilizaron grupos focales (focus group) como indican Hernández, Fernández y Baptista (2003) como la técnica de recolección de datos., la cual es una técnica 
de investigación social que trabaja con el habla, en el que se articula un orden social y la subjetividad (Buendía,1998). El estudio desarrolló dos grupos de tres y dos participantes, con sesiones similares para ambos, con una duración de una hora y media cada uno. Los participantes firmaron un consentimiento informado y llenaron un cuestionario de datos socio demográfico.

\section{Participantes}

Se convocó, a través de la dinámica "bola de nieve", por correo electrónico, con la consigna de reunir a los hombres de la comunidad guatemalteca voluntarios para participar. La convocatoria no dio los resultados esperados para completar con el número deseado de participantes en cada grupo. Se enviaron alrededor de 200 correos electrónicos y únicamente se recibieron 18 respuestas y en la convocatoria final participaron cinco hombres, tres para el primer grupo y dos para el segundo, aunque habían confirmado más. Las características de los participantes fueron que estaban comprendidos entre las edades de 27 a 49 años, todos eran profesionales graduados universitarios, cuatro de ellos con pareja y uno soltero. Todas las madres de los participantes cursaron estudios de diversificado y se dedicaron a ser amas de casa, una de ellas trabajó como secretaria. Cuatro de los padres de los participantes eran profesionales graduados universitarios, uno de ellos no terminó sus estudios. Para tres de ellos la práctica religiosa es semanal, otro la realiza mensual y otro no tiene ninguna práctica. Cuatro de ellos se definen como ladinos y uno como mestizo.

\section{Instrumento}

(técnica de producción de información).

Las interrogantes indagaron aspectos sobre la cultura de los participantes. Como sugieren Palacios-Ceña y Corral Liria (2009), se cuestionó sobre temas espontáneos, enfocados en su motivación a participar, lo que pensaban sobre las investigaciones y sobre el tema de la masculinidad.

El análisis de contenido elegido para la interpretación de los datos según PalaciosCeña D. y Corral Liria I. (2009), se hizo a través de Unidades de Significado de los textos transcritos. Las categorías propuestas para organizar los datos recolectados en los grupos fueron: Categoría 1: Cómo se convirtieron en hombres. Categoría 2: La visión social de ser hombre. Categoría 3: El significado de ser hombre. Categoría 4: Ser hombre en Guatemala. Enmarcadas en el enfoque biopsico-social.

Hallazgos

Los hallazgos encontrados en el estudio, según lo recolectado son los siguientes:

Desde lo biológico: Para ser hombres su orientación sexual tiene que ser heterosexual. Perciben que el placer sexual de la mujer lo provoca el hombre, sin embargo se plantean que no se sienten obligados a satisfacerla porque además tienen que buscar su propia satisfacción, es un trabajo de dos. La infidelidad es vista como una opción normal, como parte de ser hombre, para demostrar su potencia y virilidad.

Desde lo psicológico: El mandato es que el hombre no expresa sentimientos, principalmente a sus hijos, puede mantenerse distante emocionalmente. Este grupo de hombres quiere hacer la diferencia y ser expresivos con sus hijos varones, lo consideran una tarea ardua porque tienen que desaprenderse de este mandato social. En la relación con sus amigos el trato es rudo, con palabras soeces, brusco, pero es la expresión de su afecto. El hombre es violento, es una característica. Es protector, asume los riesgos y se siente obligado a dar la vida por su familia (esposa e hijos). La presión de proteger es interna. Tiene que 
ser el proveedor, pagar las cuentas, el empoderamiento y emancipación de las mujeres que quieren tomar esa iniciativa los incomoda.

Desde 10 social: La imagen del padre como modelo para aprender a ser hombre. La exigencia interna de seguir el modelo. El hombre no solo modela ser hombre sino también tiene que modelar la paternidad. El Padre es el jefe de casa, toma las decisiones, es la suprema autoridad, tiene que educar a sus hijos para que aprendan las asignaciones culturales como parte de su identidad. El hombre es un trabajador, por muchas horas y en un trabajo cansado. El trabajo lo convierte en el proveedor de la familia.

El machismo lo enseña la madre, es ella quien dice cómo debe ser tratado un hombre y quien asigna los roles dentro del hogar. Responsabilizan a la mujer del machismo social.

Hay tareas domésticas propias de los hombres, las que requieren fuerza física y riesgos, las cuales tienen que aprender, sino son vistos de menos. En las tareas domésticas, que culturalmente están asignadas a las mujeres, este grupo de hombres se siente con el deseo de involucrarse más, sin embargo aunque en su educación aprendieron a realizarlas, el mandato es que lo pueden hacer cuando no haya una mujer que lo haga. El grupo opina que buscar la equidad con la mujer es necesario, pero muy difícil de lograr, porque el hombre exige, pero tiene dificultad de cumplir de la misma manera. Aunque tienen un fuerte deseo de que la equidad se dé, consideran que al reflexionar sobre ello, notan que es demasiado difícil de cumplir.

Ven la metrosexualidad como una presión social, hombres estéticamente más exigentes. Se considera una moda, un estilo de vida, contextualizado en un grupo socioeconómico específico.

\section{DISCUSIÓN}

Iniciar una investigación sobre el tema fue un reto. Durante las sesiones de los grupos focales fue necesario hacer esa reflexión, pues de cierta manera, notaba que ellos se cohibían al tener que expresarse ante una mujer. Luego de lograr superar la barrera pudimos, ellos y yo, reflexionar libremente sobre qué significa para ellos ser hombres, cómo construyeron esa identidad, quiénes contribuyeron a esa formación y qué significado tiene en sus vidas.

Según los hallazgos la construcción de la masculinidad es producto de una causalidad múltiple: los mandatos sociales, que se muestran a través de la presión del grupo; el modelaje del padre que refleja ante sus ojos cómo tiene que ser un hombre, las conductas propias que debe aprender; el machismo, que indica cómo tiene que ser el rol de hombre, su conducta y atribuciones en la sociedad, a la vez que la manera como tiene que relacionarse con sus pares y con las mujeres. Todo ello determina la manera como debe manejar su sexualidad, expresar sus afectos y sentimientos, vivir su cotidianidad y utilizar el lenguaje, una experiencia que a su vez impone la fuerza, el control y el poder.

Desde el ámbito de lo biológico, en la práctica de la sexualidad hay dos construcciones claras que marcan cómo debe ser la vivencia de la masculinidad. En primer lugar, la heterosexualidad, pues aunque la homosexualidad se ve ahora con más apertura, ser hombre significa ser heterosexual. Según expresan estos hombres, ser heterosexual tiene una connotación más allá de la sexualidad, porque tiene que ver con el modo de actuar en sociedad. Espada (1998), reitera esta premisa cuando indica que la sexualidad aceptada es la heterosexualidad coital.

Para este grupo en particular, la vivencia de la sexualidad empezó desde muy temprano, como una experiencia genital. El 
objetivo de la relación era penetrar y eyacular. Luego descubrieron que había otras cosas, como el gozo, las caricias, el tiempo antes de la penetración, la seducción. Aún se considera que hay secuelas de esta forma de ver la relación sexual, muy genital, la sexualidad masculina es fálica y penetrativa.

El aspecto de la virilidad, también está marcada por la presión del grupo. Por una parte, se refiere a la vitalidad que un hombre debe tener. El hombre, para serlo, tiene que ser potente y debe compartirlo con los demás hombres para que se sepa de su potencia y de sus habilidades con las mujeres. En los círculos cerrados de hombres se hacen muchas bromas sobre las mujeres; se habla mal de ellas refiriéndose a ellas como "putas" o que quieren por mal; esto, como una lucha de poder, de quién gana, que el hombre no tiene que dejarse, de que no sea "hueco". La presión está en encajar dentro del grupo y la dinámica refuerza los cánones de la masculinidad. También están las visitas a los prostíbulos, ir a ver mujeres desnudas, dejar que se les sienten en las piernas y otras demostraciones de la virilidad y la potencia que se muestra orgullosamente en público. La conversación entre hombres también remite a la infidelidad, como una presión que el grupo ejerce y algo que debe ser una opción como parte de ser hombre.

Sexualmente, su conducta debe ir encaminada a disfrutar del acto sexual, pero no sólo él, sino a que la mujer también lo haga, ver su cara de satisfacción para saber que su rol de hombre y macho se cumplió. Además, plantean que no se sienten obligados a satisfacer, ya que además deben buscar su propia satisfacción.

Otra creencia muy arraigada según este grupo de hombres, es la de que el hombre es quien inicia la relación. Manifiestan que no han tenido problemas en que sea la mujer quien tome la iniciativa; sin embargo, es algo que parece que a ellos les corresponde y las mujeres también están esperando esta conducta.

Se destaca el deseo constante y permanente de tener relaciones. Si una mujer dice que no quiere tener sexo por algún pretexto, es muy válido, pero si el hombre no tiene deseo es mal visto. A pesar de ello, algunos han aprendido que también pueden no tener deseo en ese momento, porque están cansados después de un día de trabajo o por cualquier otra razón.

Unido a que deben ser heterosexuales para ser hombres, la preocupación que surge es el examen de la próstata; sienten alivio de que actualmente haya otras opciones para hacerlo. Se considera una debilidad el hecho de que les vaya a gustar y descubrir que pueden ser homosexuales. Se hace evidente el impacto que tiene la hegemonía de la masculinidad sobre la salud de los hombres.

La experiencia de ser hombre en la sociedad guatemalteca, en las voces de este grupo de hombres, representa un enfrentamiento con mandatos que la misma les impone y que se enmarcan en su ámbito psicológico. Desde niños tuvieron experiencias que fueron marcando la construcción de su masculinidad, la idea de cómo ser hombre. Según se expresan, se aprende a ser hombre a través del modelaje. La primera imagen con la que se identifica ser hombre es la del padre, el cual es un ícono de la identidad masculina y que modela el ser hombre. Aparece un deseo de ser cómo él, de imitarlo, sin entender claramente lo que hacía, pero de ser como él. El padre es visto como el que tiene la fuerza, el que corre los peligros, el que se expone a todo por defenderlos y no permite que algo les suceda. El recuerdo que se tiene del padre es del que todo lo puede. A la vez, es quien emerge de los problemas, quien puede resolverlos, el eje que no se quiebra, el que protege, el que cuida y 
provee "A mi papá lo considero como mi héroe, es difícil describirlo, pero él es la fuerza, el que corría los peligros por nosotros, si estaba lloviendo afuera y habia que salir, él salía, el que nos protegía, todo lo podía, me recuerdo que cuando era un niño y él todo lo podía..."

Se quiere trabajar en lo mismo que él y se desea ser como él. Se considera que lo que el padre ha realizado es lo propio: la edad a la que se casó, el trabajo que realiza, cómo lo realiza; todo ello forma ese imaginario de identidad masculina. La presión de proteger es interna, enseñada por el padre protector o quizá ellos la desean construir dentro de su forma de ser padres. "Yo hago lo mismo que hacía mi papá, tomando el ejemplo de él." Parrini (2000), reitera estas ideas cuando reflexiona sobre esas imágenes para comprender la importancia entre la paternidad y masculinidad en la formación de la subjetividad.

La relación con el padre es descrita como buena, pero no íntima, el mandato que perciben es que el hombre no tiene que expresar sus sentimientos y su afecto hacia los demás, y esa idea se manifiesta en la relación con los hijos. En algunas ocasiones el hombre intenta suplir el afecto con cosas materiales. El rol del padre es de educar, corregir, ser la autoridad e imponer la disciplina, por lo que el afecto es lo propio de la madre y, culturalmente, él puede estar al margen.

Los hombres no deben llorar 0 manifestar sus sentimientos cuando algo los afecta, más bien, el precepto viene dado de que el hombre debe replegarse ante lo que siente y no mostrarlo ante los demás, sobre todo en generaciones pasadas. . Algunos hombres de este grupo opinan que es importante expresarse e intentan hacerlo; han desaprendido el modelo hegemónico, aunque con dificultad, pero han integrado a su aprendizaje que expresar los sentimientos es algo humano, no una cuestión de género. Rodríguez-Ramírez y Toro Alfonso (2009) afirman esto al decir que las formas de expresarse emocionalmente es parte de la reproducción de categorías específicas del sujeto tales como: género, clase, sexualidad y raza, estando implícitas las relaciones de poder que las constituyen.

La forma como esto afecta la identidad de algunos de estos hombres es que ese alejamiento emocional con el padre no lo desea con sus propios hijos e intentan hacer algo diferente, pretenden vincularse $y$ comunicarse mejor con sus hijos. Es interesante que los participantes perciban al padre como cariñoso con la madre pero a la misma vez distante e incapaz de mostrar emociones con los hijos.

Se considera que sería muy fácil ser mujer, sin preocupaciones por lo económico, ni por todo lo demás que es asignado al hombre, porque no tendrían que trabajar, no tendrían complicaciones, se dedicarían a satisfacer al esposo, con todo lo que a él le agrade, sin tráfico, sin problemas, hasta tiempo para ir al gimnasio. Sin embargo, esto lo ven sin tomar en cuenta la casa y los hijos y lo que todo eso conlleva. Se destaca el planteamiento que algunos hace sobre que siendo mujeres se dedicarían a satisfacer al esposo implicando probablemente que sus esposas o parejas no necesariamente lo hacen.

Algunos hombres se sienten obligados a saber, a tener conocimiento de muchas cosas, por lo que tienen que leer, ver las noticias y estar enterados. El hombre se percibe como el sujeto supuesto a saber, a dominar y a controlar la información.

El carácter de un hombre tiene que ser fuerte, decidido, duro en sus decisiones, no tímido. Las presiones son una carga fuerte. Como hombres, tienen la responsabilidad de proteger a la familia, de hacerla crecer culturalmente, religiosamente, además deben aportar a otras personas, al país, a 
los vecinos y amigos. Ellos buscan hacer la diferencia; sin embargo es difícil. Olavarría (2001), afirma que esta construcción del hombre, en que este demuestre sus capacidades, su fortaleza y que viviendo en el ámbito público proteja y provea a la familia. Connel (2009), a su vez, habla de una definición normativa que es el modelo de ser hombre como una serie de normas de conducta que tiene que cumplir.

Las relaciones con otros hombres tienen límite y serias consideraciones. Tienen muchas ideas y creencias sobre cómo se adquiere la homosexualidad, como si fuera un padecimiento. Consideran que puede ser culturalmente adquirida y principalmente dentro del hogar. La preocupación está fundada en si eso puede gustarles o no. Temen a los acercamientos físicos entre hombres y a las manifestaciones de afecto. Los compañeros de colegio de toda la vida pueden ser abrazados y besados; sin embargo es una práctica que no se da muchas veces dentro de sus hogares. No se abrazan y besan con su padre o con los miembros masculinos de la familia, tíos, abuelos, primos etc. Cuando beben las cosas cambian, pues puede haber significativas manifestaciones de afecto que pueden llegar a besos y abrazos, siempre en el entendido de que es una relación de amigos muy cercana y que es asexual. La relación es brusca, pero eso es expresión de afecto.

Las palabras soeces son parte fundamental de la relación entre hombres. Cuando el afecto es muy grande la manera de llamarse es de "cerote" que es una palabra con un código o connotación de mucho aprecio y cariño. Los amigos son solidarios y se apoyan, pero pueden insultarse entre sí en el entendido de que son códigos de comunicación entre hombres.

En la esfera social sus recuerdos de infancia, quizá no tan elaborados, asocian ser hombre con ser trabajador. "Cuando tenía tres años, quería trabajar como mi papá". Esta idea, enmarcada en que la mujer puede o no trabajar, pero de que el hombre debe hacerlo. Este enfoque lo apoya Olavarría (2008) al afirmar que los puestos laborales se otorgan a los hombres, pues ello sustenta una masculinidad autoritaria.

El aprendizaje de cómo conducirse socialmente viene dado por lo que se observó en la conducta del padre: la cortesía, el respeto y la consecuencia. Ser obedientes con su padre, por el mismo respeto que inspiraba esa consecuencia de él, el que cumpliera con su palabra, los hace ser ahora de esa manera. Probablemente estos padres también aprendieron de sus padres el mensaje que luego pasaron a sus hijos. Este concepto reafirma lo planteado por Olavarría (2001) cuando se refiere a la obligación que se les impone a los hombres de ser rectos, responsables y de comportarse correctamente, como atributos de alto nivel moral característicos en los varones.

La paternidad juega un papel muy importante para ellos y cobra varios matices: ser protectores de sus hijos, velar por su educación, darles un buen ejemplo, como el que ellos recibieron de su padre, modelarles una imagen que puedan seguir. Adicional a esta imagen quieren enseñar a sus hijos a demostrar sus afectos y expresar sus sentimientos, o sea imitar de su padre lo positivo y no continuar repitiendo las cosas que les parecieron negativas.

El concepto de la masculinidad hegemónica que plantea Espada (2004) habla de esa fuerza y autoridad que socialmente se le pide al hombre en su conducta y en ese imaginario, la presión de grupo juega un papel preponderante. La experiencia que plantean estos hombres, la cual vinculan al modelo machista que han aprendido, habla de cómo se sienten frente a esta presión que se ejerce sobre ellos. Presión que es ejercida por un grupo que 
está conformado por las personas de su entorno: padres, amigos, mujeres, comunidad, la sociedad en pleno, que esperan ciertos comportamientos de parte suya para hacerse valer como "hombres" ante ellos. Abarca la demostración del afecto, la manera de ser padre, la práctica de la sexualidad y la vivencia de la cotidianidad.

Responsabilizan a la mujer del machismo social, "no son los hombres...son las mujeres que enseñan a sus hijos varones a ser así...' Han aprendido del padre cómo debe ser su rol. El padre les ha enseñado que hay que ser cariñoso con la esposa y que ella debe ser sumisa, así como consultarle las decisiones, aunque es el hombre quien tiene la última palabra. Como parte de las prácticas sociales que han aprendido, el hombre es el proveedor, el que paga las cuentas. Actualmente las mujeres han empezado a tomar esa iniciativa y eso los incomoda.

La construcción de la masculinidad tiene el componente de violencia. El hombre es violento, es una característica propia. "Ser violento es una característica de ser hombre." Se observan conductas violentas como querer aparecer "machitos", "brincones", que se refiere a que el hombre siente que parte de su condición implica buscar pelea. Según Olavarría (2001), que presenta una triada de violencia masculina y esta es: hacia las mujeres, hacia otros hombres y hacia sí mismos vista como un mecanismo compensatorio.

Los roles de género son diferentes, porque la cultura así lo ha marcado. Hay cuestiones que son simplemente humanas y no necesariamente se tienen que asignar a uno u otro género. En la intimidad del hogar la mujer tiene asignados roles que son propios de ella, porque así es como aprendemos. La madre regaña, revisa las tareas, atiende, pero quien pone la disciplina es el padre, él es el jefe de la casa, él es la autoridad, quien decide lo importante.

El mensaje es que las mujeres son del ámbito privado y los hombres en la escena pública. Aunque hay tareas domésticas que, por requerir más fuerza, son propias del hombre, los quehaceres propiamente dichos se han dejado a la mujer. Los hombres de este grupo se sienten más comprometidos en colaborar con los mismos. Queda claro que la responsabilidad primaria es de la mujer pero que los hombres 'conscientes' colaboran. Refieren que sus madres les enseñaron a realizarlos como parte de su formación, por si no había quién lo hiciera por ellos.

Sin embargo, las tareas que conllevan el uso de la fuerza son propias de los hombres, porque culturalmente está establecido. Serruchar, clavar, armar muebles dentro de la casa o cambiar una bombilla son trabajos que el hombre tiene que realizar. Implica su fuerza y él es quien se pone en riesgo, nunca los demás. La experiencia es que el padre puede o no incluir a los hijos en el aprendizaje de estas labores. Este grupo de hombres que participó en la discusión, desea que sus hijos aprendan estas asignaciones culturales como parte de su identidad masculina.

Por otra parte, los trabajos domésticos como lavar, limpiar y cocinar son propios de las mujeres. A pesar de ello, los aprendieron y refieren que eso fue muy educativo para ellos en casos en que tuvieron que vivir solos, les ayudó a no ser desordenados. Sin embargo, algunos indican que estas son tareas que las realizan por gusto, pero no por obligación; que no les corresponden si hay una mujer que las realice aunque hayan observado que el padre ha colaborado en las tareas domésticas con más presencia.

Si bien su deseo es ser equitativos con la mujer, ellos mismos consideran lo difícil 
que puede ser, porque exigen a la mujer ciertas cosas que ellos no consideran tan importantes de cumplir, esto muy unido a su rol de protectores. De manera que, cuando hablan de equidad la ven como muy complicada de actuar, debido a que la preocupación de la mujer por protegerlos no es importante, pues no es de ella la responsabilidad de hacerlo. Los roles que se asignan a cada género están basados en responsabilidades que cada quien tiene. El modelo positivista que plantea Connel (2009), se refiere específicamente a estos roles asignados y que se han conformado por un forjado sentido común.

En cuanto a salidas con amigos, los hombres culturalmente pueden salir con sus amigos y regresar a la hora que deseen. Esto no es igual para la mujer, quien tiene que pedir permiso y le es negado o se le impone una hora para el regreso que no puede ser transgredida. Estos hombres piensan que la mujer puede tener los mismos derechos que el hombre en cuanto a las salidas, sin embargo, no dan ejemplos de que eso es posible 0 de que lo hayan practicado.

Las presiones sociales están vigentes. Hay cosas que un hombre debe hacer para considerar que hace bien su papel. El manejo de la fidelidad en el matrimonio, muchas veces en el ámbito laboral o de amigos hay presión para que el hombre pruebe otras experiencias sexuales con mujeres, no importando si es casado y tiene hijos. Más que hacer algo en contra de su matrimonio o de la relación con su esposa es una prueba de su virilidad. El manejo de la sexualidad y el mandato de ser potente se manifiesta en esta necesidad de buscar a otras mujeres. Su afecto no cambia, sus sentimientos no se involucran, sólo es una forma de sentirse potentes. Se les puede tildar de huecos sino se animan a tener estas experiencias. El grupo presiona y es el hombre el que busca su identidad en esta presión, como parte del sentido de pertenencia a su grupo genérico. El alcohol también es un tema del que se espera el hombre participe para hacerse 0 verse como hombre ante los otros hombres.

En su trato con las mujeres refieren distintas formas de hacerlo. Aprendieron que con las mujeres hay que ser caballeroso, respetuoso, abrirles la puerta del carro; si una mujer va a subir un ascensor, hay que dejarla pasar primero. Nunca hay que ofenderlas. La imagen que guardan de sus padres es que la madre siempre consultaba al padre las decisiones, una especie de sumisión. En la relación con la esposa, ella no tiene que pedir permiso 0 consultar algo para hacerlo; puede trabajar o no hacerlo, esperan que la relación sea equitativa. Les gusta complacer a la esposa y por ello hasta dejan de hacer las actividades que disfrutan si no existen intereses mutuos, por ejemplo con el deporte. Esto parece contradecir todo el comportamiento anterior.

Con sus amigas la relación es diferente; pueden tener aventuras sexuales consensuadas con ellas, tratarlas con palabras soeces, como desplazando la relación con un hombre a una mujer, dependiendo del grado de confianza y afecto que se ha entablado. El querer llevarse bien con una mujer, amiga, compañera de trabajo o del gimnasio al tratarlas con respeto y caballerosidad, puede dar lugar a malas interpretaciones y eso pueda acarrear complicaciones en su relación de pareja o matrimonio.

En el ámbito laboral conviven con mujeres $y$, por lo tanto, se dan las oportunidades de mantener relaciones de tipo sexual, no importando si son solteros 0 casados. Uno de los participantes considera a la mujer como una oportunista, llorona y que convenientemente se queja para obtener ganancias laborales, una visión muy arraigada en su formación machista. A la vez, manifiesta que el estilo de mujer que ve es la que no trabaja, a quien mantiene el esposo, la que va directo 
al matrimonio, ve a la mujer como "ah qué bonito, tranquila la vida", "toda vez tenga muchacha y el esposo un buen trabajo, y todo lo demás". Sin embargo hace la diferencia con su mamá: ella no es igual porque si quería podía trabajar y lo hacía por el gusto de hacerlo. Esta perspectiva contrasta con el resto de los participantes, que no se expresan de esa manera, sino se cuestionan su forma machista de ser hombres y desean actuar equitativamente.

Dos términos muy coloquiales, que son "maricón" y "hueco", parecieran ser sinónimos pero no lo son, tienen significados diferentes. Sin embargo ambos términos dan cuenta de lo que se aleja de imaginario social de la masculinidad hegemónica. "Maricón significa afeminado, con conductas parecidas a las de la mujer, que besa a los hombres..."; "Hueco se refiere más bien al hombre que deja que su mujer lo mande, que no se anima a hacer algo porque su mujer lo puede regañar;" es decir, que no desea responder a la presión del grupo. La connotación es de "cobarde". Sin embargo, en la expresión verbal, pueden ser utilizados como sinónimos: si se es maricón, no se es hombre; si se es un "hueco cerote", no se es hombre.

Hay una construcción de rechazo a lo femenino que marca la homofobia. No se tienen amigos gays, más bien el trato es peyorativo; ellos indican que se aprende a ser hombre descartando ser mujer. Existe una concepción de que el homosexualismo es un comportamiento, que viene dado por la sociedad. "No se nace siendo homosexual, sino que es una cuestión cultural que comienza en casa". Todo ello marca un modo de actuar que va más allá de la orientación sexual.

Una presión que se ha dado en la modernidad de esta sociedad es la perspectiva de la "metrosexualidad". Consideran que es una moda que impone un cierto estilo de vida que está haciendo impacto a través de los medios de comunicación, buscando que el hombre sea más estético en su arreglo personal y de esa manera potencializar el mercado; esto también está contextualizado a un nivel socioeconómico específico.

Esta experiencia de ser hombre la abarca desde todas las áreas de la persona: desde lo físico y lo biológico, desde la constitución de su cuerpo y el manejo del mismo en su estilo de vida y en su sexualidad. El aspecto social, por la pertenencia al grupo genérico, el cumplimiento de los mandatos de cómo deben ser sus relaciones entre los mismos hombres y con las mujeres, así como su papel en la paternidad.

Los participantes de este estudio subrayaron profundamente el impacto del padre en sus experiencias de vida y en el proceso de conformación de su forma de masculinidad. El padre pareciera estar omnipresente en la vida de estos hombres, la masculinidad que describen la remiten al modelaje de sus padres y la influencia del tipo de hombre que fue su padre. Lo masculino en Guatemala se hace presente en décadas de conflictos bélicos, de tensión social y de exclusión de sectores indígenas (poder social, político y religioso).

Es interesante reflexionar sobre el significado de la masculinidad que se inscribe en las instancias sociales guatemaltecas y cómo se filtran en el imaginario social para dar el resultado de hombres en su carácter individual. Cabe preguntarse cuánto de la masculinidad que han construido estos participantes responde a su acción individual y a la influencia de sus padres y cuánto responde al modelo masculino de gobierno social que ha imperado en el hemisferio latinoamericano.

Los participantes declaran su deseo de hacer cambios, en su forma de actuar como hombres, intentando quebrantar algunos mandatos sociales impuestos sobre su género. Lo destaca Hartog (2006), cómo 
las nuevas corrientes teóricas de género están propiciando cambios en la manera de ser hombre, en vías de impulsar un mejor humanismo. Existe convencimiento en ciertos grupos de hombres de propiciar ese cambio. Es un reto para nuestra sociedad guatemalteca buscar medios para que estos deseos, la búsqueda de la equidad, la participación dentro del hogar, una nueva forma de paternidad más participativa y expresiva se den.

Desde esta perspectiva la consejería enfrenta el reto de dar cuenta del espacio necesario en los procesos de intervención individual del impacto del padre en Guatemala, padre que puede ser a la misma vez el padre biológico como el padre simbólico. Entre los aspectos más difíciles de cambiar, que han manifestado los participantes está: la expresión de los sentimientos y los afectos. El apoyar su expresión, otorgándoles un espacio seguro para que aprendan a hacerlo, trabajando estas ideas que los limitan y reforzar esta idea surgida, que es posible desaprender $\mathrm{e}$ integrar que, la expresión de estos es humano y no de género, puede ayudarlos.

Equidad, enraizada en su necesidad de protección es un aspecto que también es importante incluir en el trabajo clínico, especialmente en el trabajo con parejas 0 en la terapia familiar, ciertamente reconocer estas situaciones podrían propiciar insigths que a su vez resuelvan conflictos.

Como se concluyó en el Primer Encuentro de Masculinidad de Guatemala (2010), no hay apertura para cambios en las políticas públicas, pero las intervenciones que se hace uno a uno en la consejería, el trabajo en las comunidades, los espacios académicos en que incursionamos los consejeros pueden ir rompiendo estas estructuras de poder y dominación.

\section{CONCLUSIONES}

Los hallazgos de este trabajo muestran un espectro más amplio de la masculinidad que viven los hombres, cómo la manifiestan y a qué se sienten comprometidos para mantener su identidad frente a la sociedad. A la vez, nos muestran un deseo de cambiar las estructuras existentes lo que nos compromete a trabajar juntos para lograrlos.

Estos hombres han descrito de alguna manera la sociedad en la que viven y lo que ésta les exige o manda para comportarse y ser aceptados, pertenecer, en esencia es la descripción de su ciclo de vida.

Desde la consejería podemos comprometernos a propiciar estos cambios en las estructuras sociales, como los llama Hartog (2006). No podemos ser intrusivos, pero podemos hacer ver la estructura y sus consecuencias en las relaciones entre géneros.

Provocar estos cambios es un trabajo social, una deconstrucción y coconstrucción de nuevos mandatos $\mathrm{e}$ imaginarios más flexibles que formen una identidad masculina más expresiva y participativa dentro del hogar y con los hijos. Un padre más sensible que pueda acercarse a sus hijos sin el temor de ser denigrado de su categoría de hombre.

\section{Para futuras investigaciones:}

Los hombres que respondieron a la convocatoria, para participar en los grupos focales, son personas profesionales que se cuestionan el modelo machista, que buscan ser un tipo de hombre distinto. Para conocer mejor la experiencia de ser hombre en la sociedad guatemalteca se recomienda tener la visión de otros grupos de hombres, que pertenezcan a otros ámbitos para ampliar la visión. 
Guatemala es un país multiétnico, por lo que sería muy interesante conocer desde las diferentes cosmovisiones de los grupos étnicos su experiencia de ser hombre en la sociedad.

Una de las limitantes del estudio fue el hecho de que soy mujer. Pertenecer a un género distinto le da a este trabajo una visión diferente, porque hay inevitablemente otra visión del mundo que pudo haber inhibido la expresión de los participantes. Se sugiere que un estudio similar sea practicado por un investigador hombre para ampliar el espectro de los hallazgos.

\section{REFERENCIAS}

Amaral, I. S. (2000). A sociedade de consumo e a produção da toxicomania. Dissertação de Mestrado em Psicologia Social, Pontifícia Universidade Católica de São Paulo, São Paulo, SP, Brasil.

Abaunza, H. (2002). Violencia contra las mujeres: Un desastre que los hombres sí podemos evitar. En A. Campos \& J. Salas (Eds.), Masculinidades en Centro América (pp. 83-102). San José: Lara Segura Editores.

Buc, N. (2002). Aportes complementarios a la situación de la masculinidad en

Guatemala. De Campos \& Salas Masculinidades en Centro América, (págs.

175-177). San José: Lara Segura Editores.

Buendía, L. (1998). Métodos de investigación en psicopedagogía. Madrid: McGraw-Hill.

Campos A. \& Salas J. (2005). Masculinidades en Centro América. San José: Lara Segura Editores.

Connel, R. (2009). La Organización Social de la Masculinidad. Biblioteca virtual de ciencias sociales, Recuperado el 15 de octubre 2009, www.cholonautas.edu.pe

Espada, J. (2004). Poder, masculinidad y virilidad. Extracto de ponencia: Curso

Técnico Especialista en Igualdad de Oportunidades en el Empleo, IMUMEL. Impartido 7 de mayo 2004, Albacete.

Estrada, M. (2002). Educación de la masculinidad desde la escuela. Un enfoque integral. A. Campos \& J. Salas (Eds.), Masculinidades en Centro América (pp. 166-170). San José: Lara Segura Editores.

Galvan, B. (2002). Masculinidades en Centro América, balance, retos, perspectivas. Caso Guatemala. En A. Campos \& J. Salas (Eds.), Masculinidades en Centro América (pp. 171-174). San José: Lara Segura Editores.

Guerra, B. \& Toro Alfonso, J. (2009). Masculinidad y Psicoterapia. En J. ToroAlfonso (Ed.), Lo Masculino en evidencia: Investigaciones sobre la masculinidad (pp. 257-286). San Juan PR: Publicaciones Puertorriqueñas.

Hernández, R., Fernández, C., \& Baptista, P. (2002). Metodología de la investigación. México: McGraw-Hill.

Liendro, E. (2002). Dinámicas y dilemas en los aspectos teóricos y metodológicos del trabajo con hombres. En A. Campos \& J. Salas (Eds.), Masculinidades en Centro América (pp. 66-82). San José: Lara Segura Editores.

Marsellés, H. (2005). El enfoque de género y desarrollo en PESA de Centroamérica.

Honduras: PESA Centroamérica. Recuperado 1 de junio 2010. Disponible en

www.pesacentroamerica.org/.../enfoque_g enero_PESACAM.pdf

Montesdeoca, E. (2002). El abordaje de la masculinidad en Honduras: ¿un frente de batalla y/o de oportunidades? En A. Campos \& J. Salas (Eds.), Masculinidades en Centro América (pp.123-156). San José: Lara Segura Editores.

Olavarría, J. \& Parrini, R. (2000). Masculinidades. Identidad, sexualidad y familia. Primer encuentro de masculinidad. El Hombre. ¿Existe? (pp. 59-66). FLACSO- Chile, Universidad Academia de Humanismo cristiano/ red de masculinidad. Recuperado el 28 de enero 2010. Disponible en www.flacso.cl/biblioteca.php

Olavarría, J. (2001). Hombres, identidades y violencia de género. Revista de la

Academia, 6, 101 - 127. Disponible en www.flacso.cl/biblioteca.php

Olavarría, J. (2008). Globalización, género y masculinidades: Las corporaciones trasnacionales y la producción de productores. Revista Nueva Sociedad No. 218. Recuperado el 6 de septiembre 2009, www.nuso.og 
Parrini, R. (2000). Los poderes del Padre: Paternidad y subjetividad masculina. En $\mathrm{J}$. Olavarría \& R. Parrini (Comp.), Masculinidades: Identidad, sexualidad y familia. Primer encuentro de masculinidad (pp. 69-78). FLACSO- Chile, Universidad Academia de Humanismo cristiano/ red de masculinidad. Recuperado el 28 de enero 2010. Disponible en www.flacso.cl/biblioteca.php

Reyes, R. (2002). Algunas reflexiones y descripciones sobre el trabajo de hombres contra la violencia en Nicaragua. En A. Campos \& J. Salas (Eds.), Masculinidades en Centro América (pp. 103-108). San José: Lara Segura Editores.

Rodríguez-Ramírez, H. \& Toro-Alfonso, J. (2009). Las emociones y masculinidades como fenómenos culturales. En J. ToroAlfonso (Ed.), Lo Masculino en evidencia: Investigaciones sobre la masculinidad pp. 139-172). San Juan, PR: Publicaciones Puertorriqueñas.

Salas, J. (2005). Hombres que rompen mandatos. La prevención de la violencia. Costa Rica: Lara Segura \& Asociados.

Toro-Alfonso, J. (2009). Lo Masculino en Evidencia. Investigaciones sobre la Masculinidad. San Juan, PR: Publicaciones Puertorriqueñas. 